Journal of Applied Pharmaceutical Science Vol. 6 (10), pp. 055-062, October, 2016

Available online at http://www.japsonline.com

DOI: $10.7324 / \mathrm{JAPS} .2016 .601007$

ISSN 2231-3354 (cc) BY-NC-SA

\title{
Lignosulfonic Acid Based Hydrogel Nanocomposites for Antimicrobial Application
}

\author{
Chandra Sekhar Espenti ${ }^{1 *}$, K.S.V. Krishna $\mathrm{Rao}^{2}$, K. Madhu Sudana Rao ${ }^{3}$ \\ ${ }^{1}$ Department of Chemistry, Acharya Nagarjuna University, Nagarjuna Nagar, Guntur, A.P. India. ${ }^{2}$ Polymer Biomaterial Design and Synthesis Laboratory, \\ Department of Chemistry, Yogi Vemana University, Kadapa, Andhra Pradesh, India. ${ }^{3}$ Nano Information Materials Laboratory, Department of Polymer \\ Science and Engineering, Pusan National University, Busan, South Korea.
}

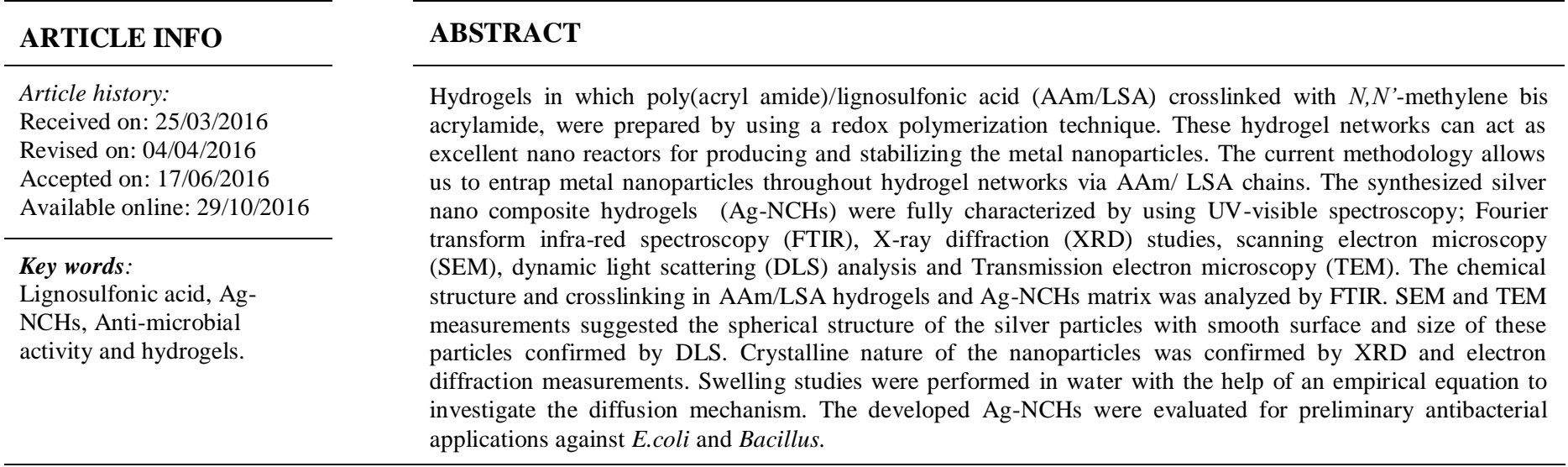

\section{INTRODUCTION}

Hydrogels based on both natural and synthetic polymers are currently receiving a great deal of interest, notably due to potential applications in the controlled release of bioactive molecules and tissue engineering. Hydrogels which are polymeric materials that have hydrophilic three-dimensional networks composed of a polymer backbone, water and crosslinking agents, capable of absorbing large amounts of water or biological fluids (Victor et al., 2013; Galed et al., 2003). One of the advantages of the hydrogels is fabrication in their capability of undergoing first-order phase transition under the change of some external parameters such $\mathrm{pH}$ (Melendez-Ortiz et al., 2015), ionic strength (Paula et al., 2002), and temperature (Lorenzo et al., 2002). There are several possible mechanisms

Corresponding Author

E-mail: chandu.ac.in @ gmail.com; Tel: +919885698480. leading to in situ gel formation: solvent exchange, UV-irradiation, ionic cross linkage, $\mathrm{pH}$ change, and temperature modulation (Chaudhary et al., 2014). Generally, polymer nanocomposites are the result of the combination of polymers and inorganic/ organic fillers at the nanometer scale. The interaction between filler components of nanocomposites at nano dimension enables them to act as molecular bridges in the polymer matrix. This is the bases for enhanced mechanical (stiffness and toughness), thermal (flammability resistance), biological, magnetic, optical, electronic, and optoelectronic properties as compared with the corresponding inorganic or polymer component only (Chia-Liang Tsai et al., 2015; Hule et al., 2007).

Lignin is a macromolecular compound more chemically active than the cellulose, hemi cellulose and other natural polymers, due to its functional groups. Globally, lignin is regarded as an unrefined material with a high recovery potential, easy to get from the renewable sources, with low costs and an insignificant pollution degree (Totolin et al., 2010; Sekhar et al., 2014). 
Lignin or lignosulfonates are waste discharged from the paper and pulp industries in bulky scale and poses enormous disposal problem (Zhang et al., 2001). Lignosulfonates are precipitated as calcium salts from spent process liquid, black liquid, from sulphite plants by means of lime, 90-95\% of the lignosulfonates is gained. In the present study the acryl amide and lignosulfonic acid were crosslinked with MBA, it is found that the inclusion of a "ineffective" but abundant and renewable source such as lignin to acrylamide hydrogel networks through graft copolymerization can improve acrylamide hydrogels salt-resistance and impart hydrogels with high metal ion adsorption capacities.

Along with various synthetic hydrophilic polymers used in the preparation of hydrogels, acrylic monomers such as acrylamide (AAm), acrylic acid (AAc), and their derivatives, have been extensively used in the synthesis of hydrogels (Ramli et al., 2013; Maitra et al., 2014). Poly(acryl amide) based copolymers have found to be significant materials in agriculture, horticulture, adsorbents, biomedical and pharmaceutical fields.

It is widely accepted that the improved absorption capacity or absorption rate can be achieved for acrylamide polymers by incorporation of various hydrophilic units. The swelling property of these materials directly measures its function in environmental applications as an adsorbent and as biomaterial in medical, pharmaceutical, and biological applications. The optimized AAm-LSA hydrogels show good water absorbency and ability to high metal ion $\left(\mathrm{Ag}^{+}\right)$adsorption. At the same time, a new way to consume lignin has been developed (Tiina et al., 2014). The antimicrobial property of silver is related to the amount of silver and the rate of its release. Silver in its metallic state is inert but it reacts with the moisture present in the skin and the fluid of the wound and gets ionized. The ionized silver is highly reactive, as it binds to tissue proteins and brings structural changes in the bacterial cell wall and nuclear membrane leading to cell distortion and death (Alexander et al., 2015). Silver also binds to bacterial DNA and RNA and by denaturing inhibits bacterial replication (Sudana Rao et al., 2013; Chopra 2007).

\section{MATERIAL AND METHODS}

\section{Materials}

An analytical Reagent grade sample of Lignosulfonic acid (LSA) from SIGMA ALDRICH, (USA); Acryl amide (AAm), Silver nitrate $\left(\mathrm{AgNO}_{3}\right)$ were received from MERCK, (Mumbai, India); $N, N$-methylene bis acrylamide (MBA), Potassium per sulfate (KPS) were from s.d. Fine chem limited (Mumbai, India); Tetramethylethylenediamine (TEMED) is from Sisco Research Laboratories Pvt. Ltd. Mumbai; Sodium Borohydrate $\left(\mathrm{NaBH}_{4}\right)$ from QUALIGENS Fine Chemicals (Mumbai, India). All Chemicals were used without further purification and double distilled (DD) water was used throughout the experiments.

\section{Preparation of AAm/LSA hydrogels:}

Hydrogels were prepared by free radical redox polymerization. Briefly $1 \mathrm{gm}$ of acrylamide was dissolved in 10 $\mathrm{mL}$ of double distilled water to this various amounts of LSA $(0.1$, 0.075, 0.6, 0 gm), N.N'-Methylenebisacrylamide (0.1, 0.125 gms), 0.01 gms of KPS followed by adding $1 \mathrm{~mL}$ of $1 \%$ TEMED solution as represented in the scheme 1 and all formulation codes are fitted in Table 1. And then this solution mixture was kept in water both at $65{ }^{\circ} \mathrm{C}$ for 3 hours. These hydrogels were cooled at room temperature and washed with distilled water for removal of unreacted particles, dried at $40{ }^{\circ} \mathrm{C}$ in hot oven for 24 hours.

\section{Preparation of Ag-NCHs}

The dried hydrogels were equilibrated in double distilled water for 2 days. After the hydrogels were immersed into $50 \mathrm{~mL}$ of $2 \mathrm{gm} / 500 \mathrm{~mL} \mathrm{AgNO}_{3}$ solution and allowed to equilibrate for 1 day. The most of the $\mathrm{Ag}$ ions were occupied in the free spaces of hydrogel network through $-\mathrm{CONH}_{2},-\mathrm{OH},-\mathrm{COOH}$ of hydrogel chains. The Ag ion loaded hydrogels were transferred in beaker containing $20 \mathrm{~mL}$ of $(0.02 \mathrm{~mole} / 100 \mathrm{~mL}) \mathrm{NaBH}_{4}$ solution and allowed for $12 \mathrm{~h}$ to reduce silver ions to silver nanoparticles as shown in the graphical abstract (scheme 2). The Ag-NCHs were dried for further studies.

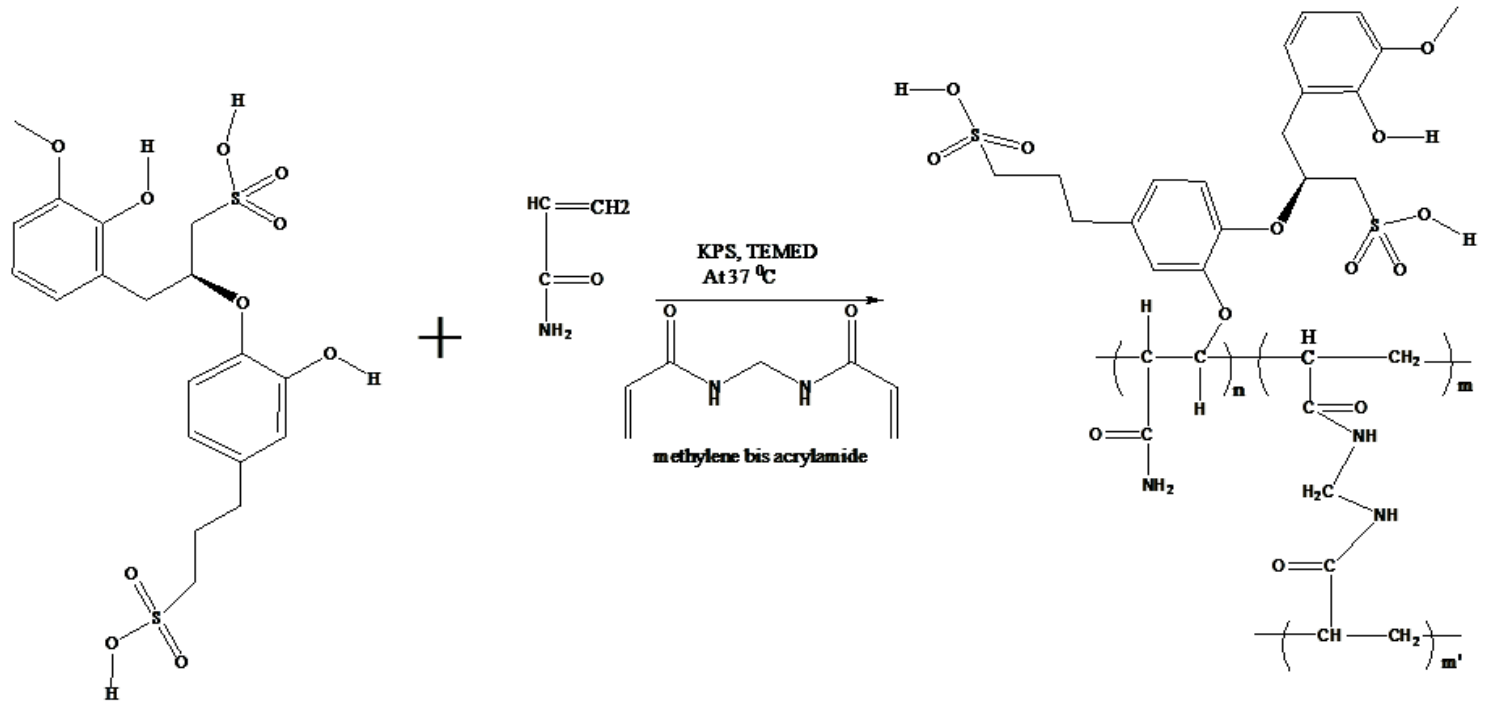

Scheme 1. Schematic representation of formation of hydrogels. 
Table 1: Feed compositions for different formulations and swelling kinetic parameters.

\begin{tabular}{|c|c|c|c|c|c|c|c|c|}
\hline Sample Code & AAm (mg) & LSA (mg) & BIS (mg) & KPS (mg) & $\begin{array}{l}\text { TEMED } \\
(1 \%) \mathrm{mL}\end{array}$ & $\mathbf{k}$ & $n$ & $\begin{array}{c}\text { Correlation } \\
\text { coefficient }\left(r^{2}\right)\end{array}$ \\
\hline AAm-LSA1 & 1000 & 0.100 & 0.100 & 0.01 & 1 & 1.799 & 0.0536 & 0.9808 \\
\hline AAm-LSA2 & 1000 & 0.075 & 0.100 & 0.01 & 1 & 1.633 & 0.0485 & 0.9743 \\
\hline AAm-LSA3 & 1000 & 0.060 & 0.125 & 0.01 & 1 & 1.738 & 0.0611 & 0.9672 \\
\hline AAm-LSA4 & 1000 & 0.075 & 0.100 & 0.01 & 1 & 1.273 & 0.0367 & 0.9928 \\
\hline AAm-LSA5 & 1000 & ----- & 0.100 & 0.01 & 1 & 1.127 & 0.0867 & 0.9797 \\
\hline
\end{tabular}

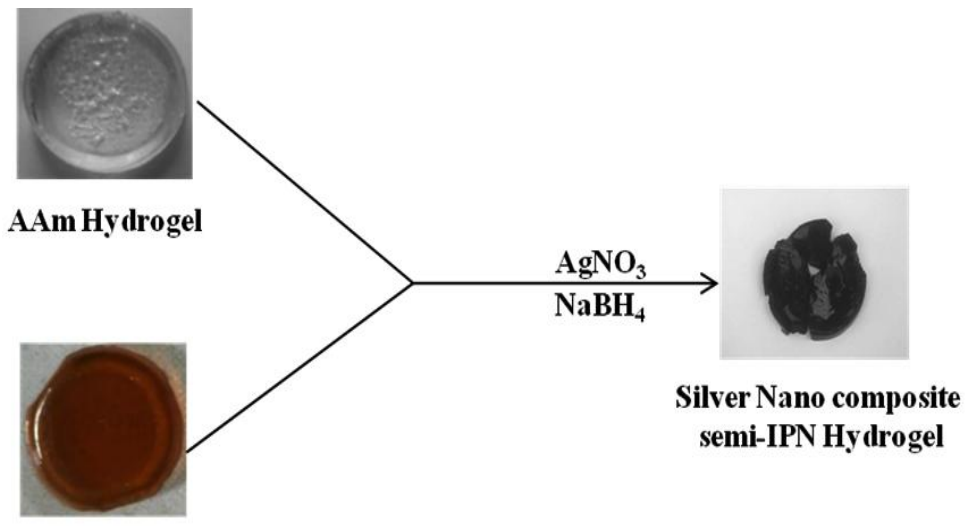

AAm-LSAHydrogel

Scheme 2. Graphical abstract of formation of SNCHs.

\section{CHARACTERIZATION}

\section{UV-visible spectroscopic analysis}

The synthesized silver nanoparticles by reducing silver metal ion solution with hydrogels and $\mathrm{Ag}-\mathrm{NCHs}$ matrix were initially characterized by UV visible absorption spectroscopy. The samples were taken in a $1 \mathrm{~cm}$ quartz cuvette and measured in a LAB INDIA, UV-3092 spectrophotometer containing double beam in identical compartments each for reference and test solution from $300 \mathrm{~nm}$ to $600 \mathrm{~nm}$.

\section{Fourier transform infrared spectroscopy}

(Perkin Elmer Spectrum Two, UK) analysis was performed to identify the chemical structure and crosslinking in AAm/LSA hydrogels and Ag-NCHs matrix. Hydrogels were finely ground with spectroscopic grade $\mathrm{KBr}$ to prepare pellets using a hydraulic pressure of $600 \mathrm{~kg} / \mathrm{cm}^{2}$ to scan the spectra between $4000-400 \mathrm{~cm}^{-1}$.

\section{X-ray Diffraction studies}

X-ray diffraction measurements were recorded using a Rigaku diffractometer $(\mathrm{Cu}$ radiation, $\lambda=0.1546 \mathrm{~nm}$ ) running at 40 $\mathrm{kV}$ and $40 \mathrm{~mA}$ and were recorded in an angle of $5-60{ }^{\circ} \mathrm{C}$ at a speed rate of $5 \% \mathrm{~min}$ to estimate the crystallinity of the sample.

$\mathrm{X}-\mathrm{RD}$ study helps to find the crystallinity of drug in the Ag-NCHs. SEM (MERAIITESCAN) images of silver nanocomposites were recorded using a JSM 6400 SEM (JEOL Ltd., Akishima, Tokyo, Japan) at X5 and X100 magnifications.
Working distance of $8.5-9.5 \mathrm{~mm}$ was maintained and the acceleration voltage used was $10 \mathrm{kV}$, with the secondary electron image (SEI) as a detector. Mean diameter and size circulation of the nanoparticles were determined by dynamic light scattering (DLS) method using a Brookhaven BI-9000 AT instrument (Brookhaven Instruments Corporation, USA).

\section{Transmission electron microscopy}

Samples of synthesized Ag-NCHs were prepared by placing a drop of the colloidal solution on carbon-coated copper grids, allowing the films on the TEM (HR-TEM, JEOL JEM2010, Accelerating voltage of $200 \mathrm{kV}$ ) grids to stand for two minutes, removing the excess solution with blotting paper, and letting the grid dry prior to measurement.

\section{Swelling studies}

Completely dried AAm/LSA hydrogel and AAm/LSA nanocomposite (Ag-NCHs) $(\sim 50 \mathrm{mg})$ were equilibrated in distilled water at $30{ }^{\circ} \mathrm{C}$ for 3 days. The equilibrium swelling capacity of AAm/LSA hydrogel and AAm/LSA nanocomposite was calculated following the equation:

$\%$ Water uptake $=\left(\frac{\left(W_{1}\right)-\left(\mathrm{W}_{2}\right)}{\left(W_{2}\right)}\right) \times 100$

Where $W_{1}$ is weight of swollen hydrogel and $W_{2}$ is weight of weight of the dried hydrogel. 


\section{Antibacterial activity studies}

Synthesized Ag-NCHs are tested for inhibition against the human pathogenic bacteria and antimicrobial activity assay are carried out by Kelman et al. disc diffusion method (Kelman et al., 2001). Mueller Hinton Agar (M173) plates were prepared for rapid growth of Bacillus subtilis (Gram positive) and Escherichia coli (Gram negative) bacteria for this study. The medium was sterilized at $121{ }^{\circ} \mathrm{C}$ and $15 \mathrm{lbs}$ for $15 \mathrm{~min}$ in an autoclave and plates were equipped with a depth of about $4 \mathrm{~mm}$. The cultures were transferred to the centre of an agar plate autonomously and spread evenly over the surface with a sterile bent-glass rod (purveyor). $10 \mu \mathrm{L}$ of $\mathrm{Ag}-\mathrm{NCHs}$ solution and was impregnated onto filter paper discs of $6 \mathrm{~mm}$ diameter, which were prepared by using Whatman grade No.1 Filter paper under aseptic conditions with different concentrations of Ag-NCHs solution (100, 150, 200, 250, 300 $\mathrm{mg} / \mathrm{mL}$ ), then positioned onto a cultured Mueller Hinton agar plates using a mechanical dispenser or sterile forceps. The plates were incubated for 18 to 20 hours at $37{ }^{\circ} \mathrm{C}$ in the incubation chamber. Antibacterial activity can be resolute by comparing the zone diameter obtained with the acknowledged zone diameter size for susceptibility (Tetracycline).

\section{RESULTS AND DISCUSSIONS}

\section{FTIR Spectroscopic analysis}

Fig (1.A.): The spectra of FTIR demonstrate the changes signifying the successful crosslinking reaction within the hydrogel formation (Scheme 1). The spectrum of the starting lignosulfonates contains peaks at $3408 \mathrm{~cm}^{-1}$ due to $-\mathrm{OH}$ stretching in phenols; aromatic skeletal vibrations peak at $1600 \mathrm{~cm}^{-1}$; at 1451 $\mathrm{cm}^{-1}$ is due to $-\mathrm{CH}$ stretching of methyl or methylene groups.

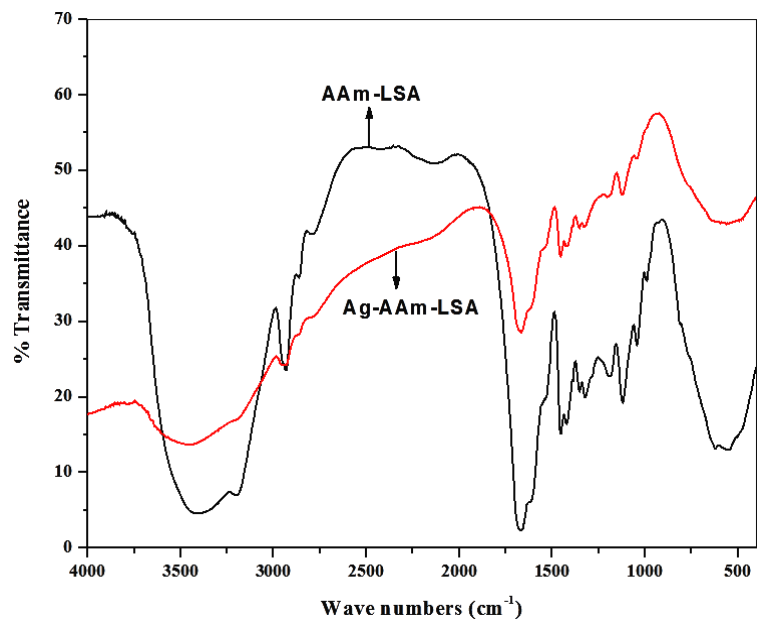

Fig. 1: FTIR Spectra of (A) SNCHs hydrogels, (B) AAm-LSA hydrogels.

The peak at $1040 \mathrm{~cm}^{-1}$ is the result of $-\mathrm{OH}$ stretching of primary alcohols. Peaks at 1190 and $550 \mathrm{~cm}^{-1}$ are due to the $-\mathrm{S}=\mathrm{O}$ stretching in sulfonic acids and $-\mathrm{SO}_{2}$ scissoring, respectively. A sharp peak at $1666 \mathrm{~cm}^{-1}$ corresponds to conjugated $\mathrm{C}=\mathrm{O}$ peak of amide group of acrylamide present in hydrogel network. The peak at $2930 \mathrm{~cm}^{-1}$ corresponds to the alkane $\mathrm{C}-\mathrm{H}$ group in the LSA. The peak at $1117 \mathrm{~cm}^{-1}$ is the result of C-O stretching of primary alcohols. The peaks of alkyne groups are too weak to visible at $2139 \mathrm{~cm}^{-1}$. Fig (1.B.): The spectrum of the AAm/LSA hydrogels was characterized by the presence of the absorption bands typical of the pure components and the silver loaded hydrogels. Due to the interaction of silver nanoparticles with the hydrogel networks, the vibrations are lesser in Ag-NCHs spectrum when compared to pristine AAm-LSA hydrogels. It showed that shifted frequencies of the of groups/bonds due to free O-H stretching (at $3467 \mathrm{~cm}^{-1}$ ), $\mathrm{C}=\mathrm{O}$ stretching vibrations (around $1670 \mathrm{~cm}^{-1}$ ), $1118 \mathrm{~cm}^{-1}$ for $\mathrm{C}-\mathrm{O}$, $2935 \mathrm{~cm}^{-1}$ for alkane $\mathrm{C}-\mathrm{H}$, and $1452 \mathrm{~cm}^{-1}$ is due to $-\mathrm{CH}$ stretching of methyl or methylene groups. And $\mathrm{S}=\mathrm{O}$ stretching vibration is shifted to $548 \mathrm{~cm}^{-1}$.

\section{Identification of silver ion in the hydrogel network}

The surface plasmon resonance (SPR) absorption peak plays a major role in the determination of optical absorption spectra of metal nanoparticles that shifts to a longer wavelength with increase in particle size. The size of the nanoparticle implies that it has a large surface area to come in to contact with the bacterial cells; therefore, it will have higher percentage of interaction when compared to bigger particles (Agnihotri et al., 2014; Bondarenko et al., 2013).

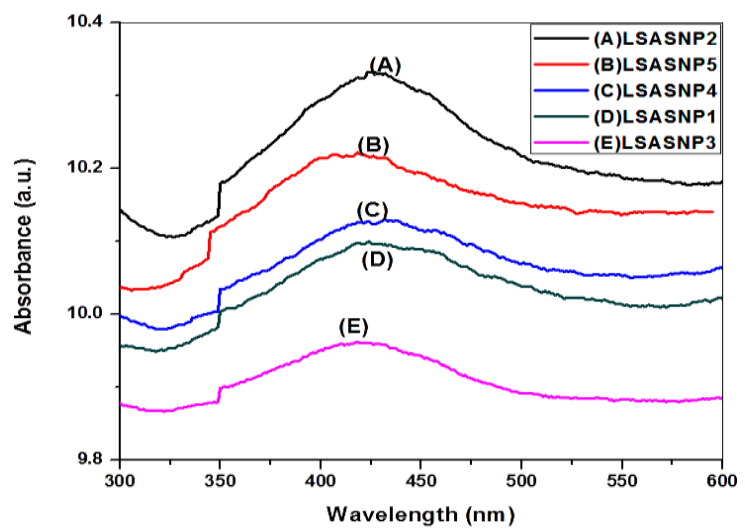

Fig 2. UV-visible spectra from $300-600 \mathrm{~nm}$ for all formulations of silver nano composite hydrogels.

The formation of Ag-NCHs in the copolymeric hydrogel networks can be expected in our current strategy because the silver salts loaded hydrogels are readily reduced by AAm-LSA hydrogels, which immediately turn into dark brown colour. This change in colour shows that the Ag-NCHs were entrapped inside the networks through strong localization and stabilization established by the polymer chains. The existence of Ag-NCHs in the gel networks were estimated by UV-visible spectroscopy analysis. Fig 2 illustrates the absorption peaks of Ag-NCHs in 300-600 $\mathrm{nm}$ range that are assigned to silver nanoparticles which arise from the SPR absorption peak. A significant improvement in the absorption peak at $\lambda_{\max }=425 \mathrm{~nm}$ was observed for Ag loaded hydrogels due to the SPR. No additional absorption peaks around 300-600 nm indicates that AAm-LSA hydrogel network is protecting the nanoparticles from the aggregation or cluster 
formation. Among those formulations Ag-AAm-LSA2 is gave a high intense peak at $425 \mathrm{~nm}$ and remaining formulations shows around $425 \mathrm{~nm}$. This analysis confirms the formation of highly dispersed Ag-NCHs in the hydrogels.

\section{X-ray Diffraction studies (XRD):}

To study the crystallographic nature of Ag-NCHs, XRD analysis was performed and XRD is shown in Fig 3. Plain hydrogels have not exhibited any sharp peaks in XRD. A broad peak at $25^{\circ}$ is due to the polymer network. In the case of AgNCHs, sharp peaks are observed at $2 \theta=22^{\circ}, 28^{\circ}, 31^{\circ}, 33^{\circ}, 37^{\circ}$, and $47^{\circ}$. The precise X-ray diffraction patterns indicate the formation of highly crystalline silver nanoparticles (Balaji et al., 2009). The results also indicate that the prepared nanoparticles are face centered cubic structure (Vasireddy et al.,2012) further conformed by electron diffraction pattern of TEM as shown in Fig 5C.

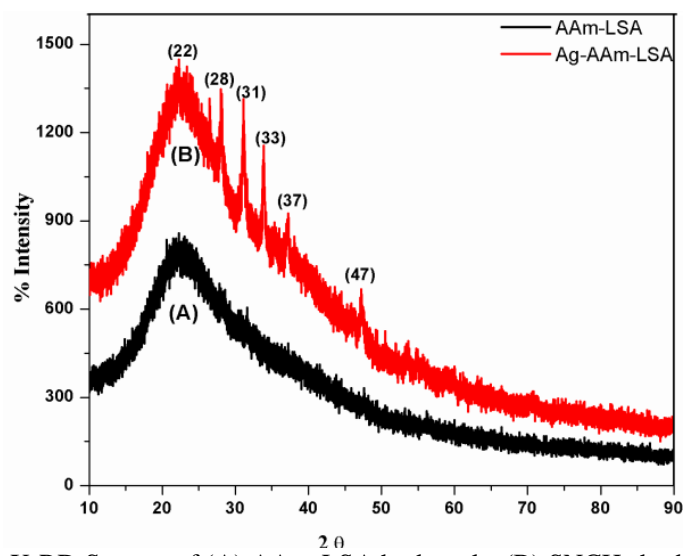

Fig. 3: X-RD Spectra of (A) AAm-LSA hydrogels, (B) SNCHs hydrogels.

\section{SEM}

Scanning electron microscopic photographs significantly showed that the smooth surface of the hydrogels and enhanced the
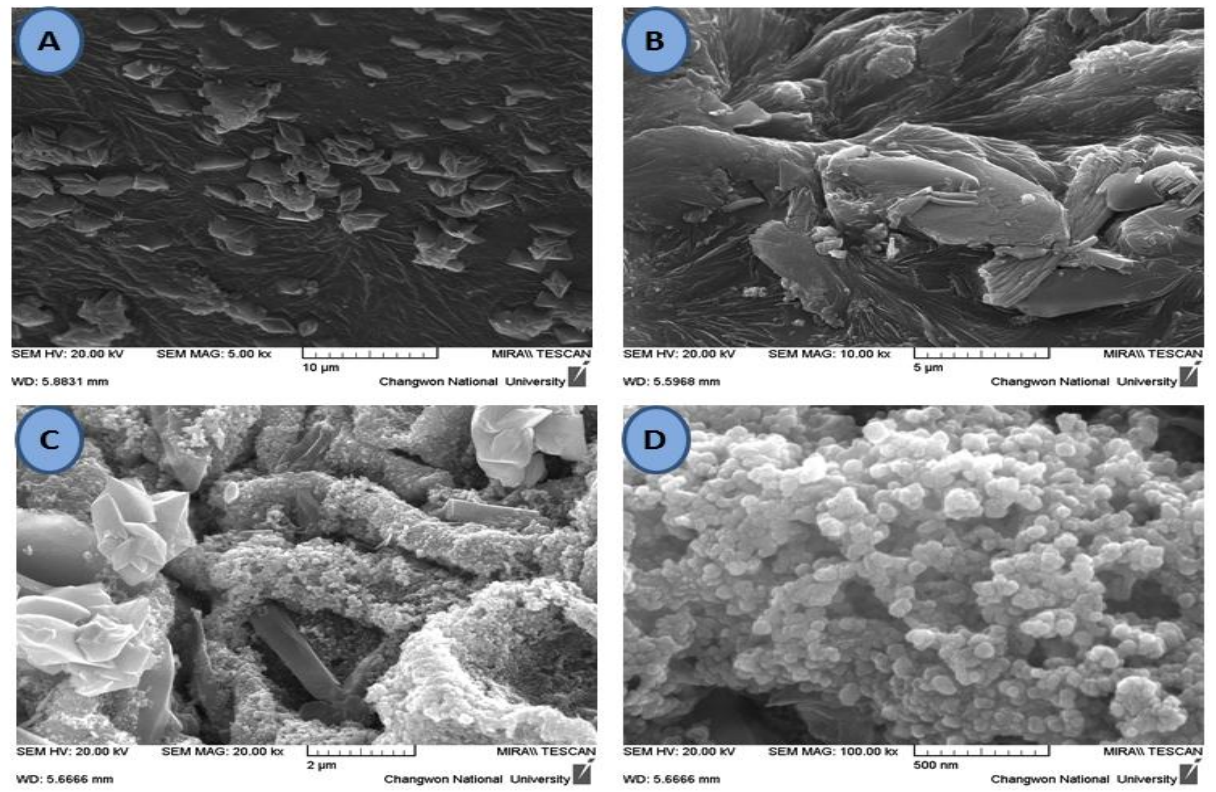

Fig. 4: Scanning electron microscopic images of AAm-LSA hydrogels at different magnifications. mechanical properties for the absorption of metal ions. The crosslinked AAm-LSA hydrogels displayed in fig 4 (A-D) the average sizes of spheres is around $10 \mu \mathrm{m}$ with spherical in shape and smooth surface. As shown by the Fig 4 results, the main advantage of the current technique is that it provided a controlled and uniform distribution of nanoparticles within the hydrogel network.

\section{TEM and DLS}

In Fig 5 TEM images of Ag-NCHs specifies that particle size, polydispersity, and location of the silver nanoparticles inside and outside of the hydrogel network. The particles are spherical in shape and constricted size distribution with an average diameter of around $25 \mathrm{~nm}$ (Fig 5A \& 5B) without any agglomeration. In the case silver nanoparticles surrounded hydrogels showed highly dissemination of nano range silver particles in the hydrogel network. The high resolution image clearly showed that the crystalline nature of $\mathrm{Ag}-\mathrm{NCH}$ covered by the hydrogel polymer chain networks. This clearly signifies higher polymer gel networks favor for the Ag-NCHs formation because the feed composition permits the establishment of inter and intramolecular attractions between the hydrogel networks due to less free space in the hydrogel networks. This porosity ultimately helps to controlling the size of the nanoparticles and also provides better stabilization of silver nanoparticles for longer periods. The size of Ag-NCHs are also measured by DLS and the average size of the particles is $24.07 \mathrm{~nm}$ (Fig 5D). Size and shape of the Ag-NCHs are imperative for the nanoparticles release on the pathogenic bacteria (Acharya et al., 2009); as a result easy and effective control concluded the carrier size is of great significant. The electron diffraction pattern of $\mathrm{Ag}-\mathrm{NCHs}$ is evidently visible in Fig 5C and diffraction rings are (111), (200) and (220) reflections indicated the Ag-NCHs are crystalline in nature and face centered cubic (fcc) network structure. 

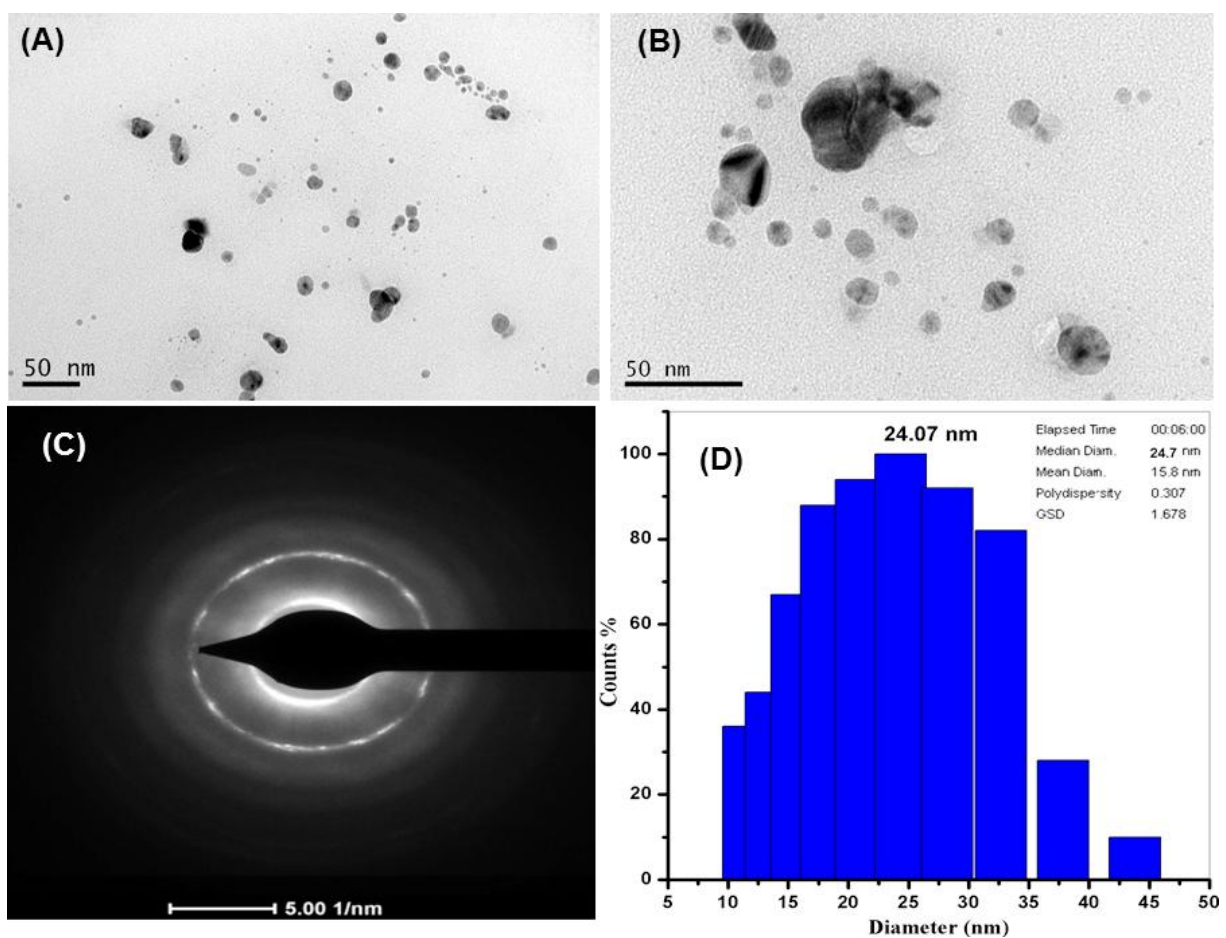

Fig. 5: Transmission electron microscopic images and DLS of SNCHs hydrogels.
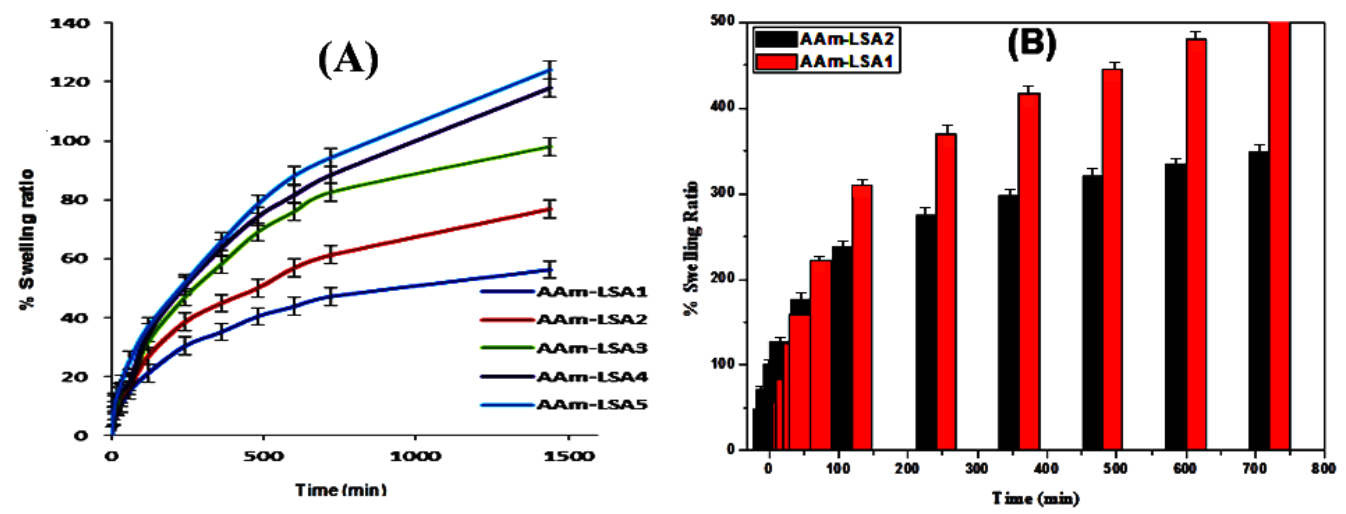

Fig. 6: (A) Swelling behavior of hydrogels, (B) Effect of monomer content on swelling behavior of hydrogels; AAm-LSA1 (0.1 mg), and AAm-LSA4 (0.075 $\mathrm{mg}$ ), (C) Effect of Cross linker on swelling behavior of hydrogels AAm-LSA3 (0.125 mg), and AAm-LSA4 (0.1 mg) and (D) Effect of silver ion on the swelling behavior of hydrogels.

\section{Swelling Studies}

In the present study, the swelling capacity of AAm/LSA composed in various formulations as shown in Fig 6A. This is due to presence of more hydrophilic groups such as $-\mathrm{NH}_{2},-\mathrm{COOH}$ in the crosslinked polymer networks, which assist to improve the swelling. If the monomer content is increased the swelling of the hydrogels also increased due to the increase of hydrophilic groups in gel network (Fig 6B).

This pattern of swelling is reasonable for $\mathrm{Ag}-\mathrm{NCHs}$ because once the $\mathrm{Ag}-\mathrm{NCHs}$ are formed inside the polymer networks, the overall porosity of the system increases which allows for more number of water molecules inside the hydrogel network. The other reason may be that the formed nanoparticles have different sizes with different surface charges in the gel networks causing absolute expansion of the networks (Siraj et al., 2013). Increase of crosslinker concentration in the hydrogel synthesis leads to decreased swelling capacities of hydrogels (Fig 6C). The observed fall in swelling ratio is quite obvious because with increasing crosslinker concentration the crosslink density increases to an appreciable extent and does not favor penetration of water molecules into the network and, therefore, the swelling of hydrogel decreases. Another reason for the observed decrease in swelling ratio is quite expected as increase in crosslinker makes the hydrogel more and more compact (Seddiki et al., 2013). Fig $6 \mathrm{D}$ represents the effect of silver ion concentration on the swelling behaviour of the Ag-NCHs. In this study loading of $\mathrm{Ag}^{+}$ions leads to gradually decrease the swelling capacities of hydrogels due to the voids of hydrogel networks are occupied by silver ions. 

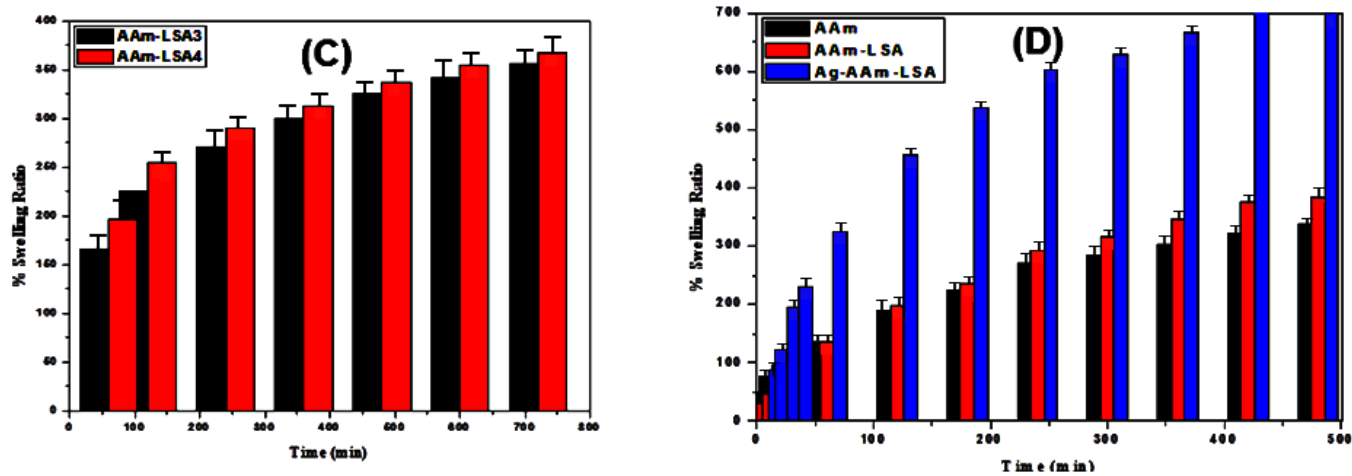

Fig. 6: (C) Effect of Cross linker on swelling behavior of hydrogels AAm-LSA3 (0.125 mg), and AAm-LSA4 (0.1 mg) and (D) Effect of silver ion on the swelling behavior of hydrogels.

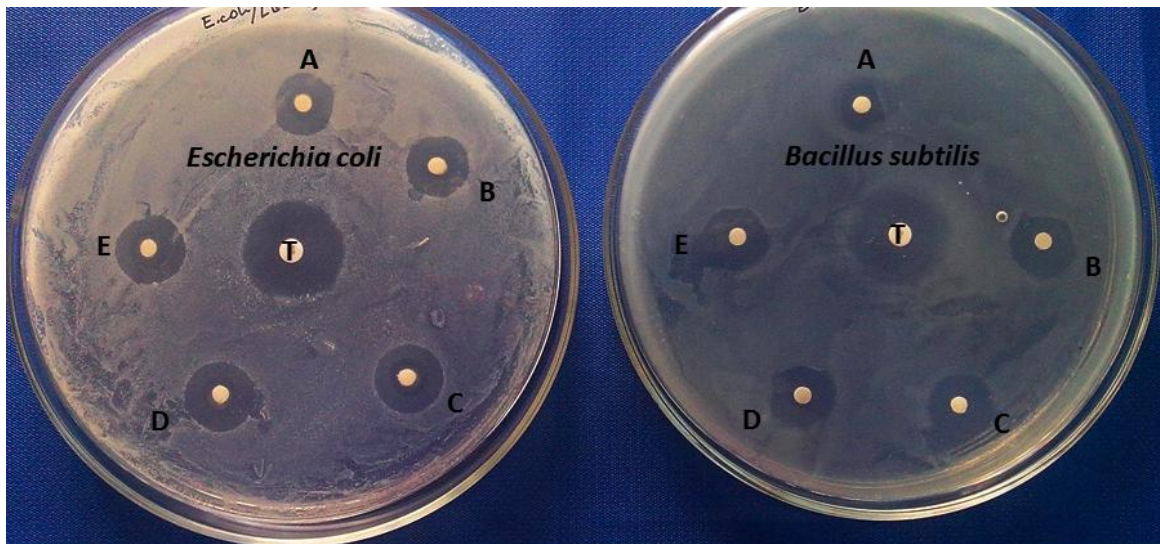

Fig. 7: Photograph showing bacterial colonies (mm) petri plates containing SNCHs-2 with concentrations of A-100, B-150, C-200, D-250, E-300 mg/mL, And Ref: T: Tetracycline.

Table 2: Diameter zone of inhibition (in $\mathrm{mm}$ ) by SNCHs-2 against human pathogenic bacteria.

\begin{tabular}{|c|c|c|c|c|c|c|c|c|c|c|}
\hline & \multicolumn{2}{|c|}{$100 \mathrm{mg} / \mathrm{mL}(\mathrm{A})$} & \multicolumn{2}{|c|}{$150 \mathrm{mg} / \mathrm{mL}(\mathrm{B})$} & \multicolumn{2}{|c|}{$200 \mathrm{mg} / \mathrm{mL}(\mathrm{C})$} & \multicolumn{2}{|c|}{$250 \mathrm{mg} / \mathrm{mL}$ (D) } & \multicolumn{2}{|c|}{$300 \mathrm{mg} / \mathrm{mL}(\mathrm{E})$} \\
\hline & Bacilli & E.coli & Bacilli & E.coli & Bacilli & E.coli & Bacilli & E.coli & Bacilli & E.coli \\
\hline AVG & 14.68 & 16.68 & 15.78 & 17.58 & 14.54 & 18.14 & 16.59 & 15.59 & 14.22 & 16.22 \\
\hline SD & 0.3544 & 0.5462 & 0.4460 & 0.2602 & 0.1737 & 0.2148 & 0.3301 & 0.3738 & 0.32125 & 0.402 \\
\hline
\end{tabular}

\section{Biological Activity}

Composed Ag-NCHs were screened for their antibacterial activity. All these hydrogel composites were possessed variable antibacterial activity against both Grampositive (Bacillus subtilis) and Gram-negative (Escherichia coli) bacterial activity against Tetracycline. Positive and negative controls produced significantly sized inhibition zones against the tested bacteria. On the basis of maximum inhibitory activity shown against Gram positive-bacteria, Ag-NCHs-2 were found to be most effective against Gram-negative with zone of inhibition fitted in Table 2 with respect to the following concentrations (100, 150, 200, 250, $300 \mathrm{mg} / \mathrm{mL}$ ). Maximum zone of inhibition $18.14 \mathrm{~mm}$ for $250 \mathrm{mg} / \mathrm{mL}$ (Fig 7) was found in Escherichia coli and transitional activity was revealed against Gram-positive. The presence of the porous hydrogel accelerates frequent diffusion of liquid media across the hydrogel which could release silver nanoparticles into it (Vimala et al., 2011). The inhibition zone diameter that is produced will specify the susceptibility or resistance of a bacterium to the silver loaded hydrogels. Ag-NCHs retain the chemical stability and appropriate smaller size which make them relaxed to interact with pathogenic bacteria (Rai et al., 2009).

The enhanced activity may be due to the Ag-NCHs particles were smaller size in nano size, enlarged surface area and high probing energy and the positively charged hydrogen on the hydroxyl group of polymer chain has been the potential to associate with the negatively charged phosphates on cell wall of the tested bacteria (Chapot-Chartier et al., 2014; En Huang et al., 2014). Therefore, such nanosized metal particles could effectively bind the substrate on the cell membrane of the microorganisms. 


\section{CONCLUSIONS}

A simple free radical polymerization technique for the synthesis of cross-linked AAm/LSA hydrogel for production of silver nanoparticles is established in the present study. The formation of crosslinked network was confirmed by FTIR spectroscopy. Nano composites prove a characteristic surface plasmon band around $\lambda_{\max }=425 \mathrm{~nm}$ for the subsistence of $\mathrm{Ag}$ nanoparticles surrounded by the hydrogel and these gels are found to be stable under ambient conditions. Results attained with SEM, TEM and UV-visible studies designate that more number of Ag nanoparticles with no individual change in morphology is formed within the hydrogel matrix, on increasing the concentration of $\mathrm{Ag}^{+}$ ions. Compared with pure AAm/LSA gel, the Ag-NCHs display supplementary equilibrium swelling and electron transfer resistance, which are reliant on the amount of $\mathrm{Ag}$ nanoparticles present in the hydrogel network. The antibacterial activity of AgNCHs suspension showed enhancement the activity towards E.coli and Bacillus.

\section{Financial support and sponsorship: Nil.}

Conflict of Interests: There are no conflicts of interest.

\section{REFERENCES}

Acharya H., Sung J., Shin H., Park S. Y., Min B. G., Park C., "Control over the surface plasmon band of block copolymer/Ag/Au nanoparticles composites by the addition of single walled carbon nanotubes" React Funct Poly, 2009; 69: 552-557.

Agnihotri S., Mukherjia S., Mukherji S., "Size-controlled silver nanoparticles synthesized over the range 5-100 $\mathrm{nm}$ using the same protocol and their antibacterial efficacy" RSC Advances, 2014; 4: 39743983.

Alexander P. Richter1, Joseph S. Brown1, Bhuvnesh Bharti, AmyWang, Sumit Gangwal, Keith Houck, Elaine A. Cohen Hubal, Vesselin N. Paunov, Simeon D. Stoyanov, Orlin D. Velev. An environmentally benign antimicrobial nanoparticle based on a silverinfused lignin core. Nature Nanotechnology 10, 817-823 (2015) doi:10.1038/nnano.2015.141

Balaji D.S., Basavaraja S., Deshpande R., Mahesh D.B., Prabhakar B.K., Venkataraman A., Extracellular biosynthesis of functionalized silver nanoparticles by strains of Cladosporium cladosporioides fungus. Colloid Surf. B: Biointerf, 2009; 68(1): 88-92.

Bondarenko O., Ivask A., Kakinen A., Kurvet I., Kahru A., "Particle-Cell Contact Enhances Antibacterial Activity of Silver Nanoparticles". PLoS ONE., 8(5), e64060. doi:10.1371/journal.pone.0064060, 2013.

Chaudhary B., Verma S., "Preparation and Evaluation of Novel in Situ Gels Containing Acyclovir for the Treatment of Oral Herpes Simplex Virus Infections" The Scientific World Journal, 2014, 7 pages, 2014. doi:10.1155/2014/280928.

Chia-Liang Tsai, Guey-Sheng Liou, "Highly transparent and flexible polyimide/ZrO2 nanocomposite optical films with a tunable refractive index and Abbe number" Chem Com, 2015; 51: 13523-13526.

Chandra Sekhar E., Krishna Rao K.S.V., Raju RR., Chitosan/guargum-g-acrylamide semi IPN microspheres for controlled release studies of 5-Fluorouracil. J App Pharm Sci, 2011; 01 (08): 199. 204.

Chopra I., "The increasing use of silver-based products as antimicrobial agents: a useful development or a cause for concern?" J Antimicro Chemotherapy, 2007; 59: 587-590.

Chapot-Chartier, Kulakauskas: Cell wall structure and function in lactic acid bacteria. Micro Cell Fact, 2014; 13(Suppl 1):S9.
En Huang, Ahmed E., Yousef, The Lipopeptide Antibiotic Paenibacterin Binds to the Bacterial Outer Membrane and Exerts Bactericidal Activity through Cytoplasmic Membrane Damage. Appl Env Microbio, 2014; 80: 2700-2704.

Galed G., Valle M.E.F., Monal W.A., "Effect of Chemical Crosslinking on the Swelling and Shrinking Properties of Thermal and $\mathrm{pH}-$ Responsive Chitosan Hydrogels" Macromol Biosci, 2003; 3: 612-619.

Hule R.A., Pochan D.J., "Polymer nanocomposites for biomedical applications" MRS Bulletin, 2007; 32: 354-358.

Kelman D., Kashman Y., Rosenberg E., Ilan M., Iirach I., Loya Y., "Antimicrobial activity of the reef sponge Amphimedon viridis from the Red Sea: evidence for selective toxicity" Aqu Micro Eco, 2001; 24: 916.

Lorenzo C.A., Concheiro A., "Reversible adsorption by a $\mathrm{pH}-$ and temperature-sensitive acrylic hydrogel" J Contr Rel, 2002; 80: $247-$ 257.

Maitra J., Shukla V.K., "Cross-linking in Hydrogels - A Review" American J Poly Sci, 2014; 4: 25-31.

Melendez-Ortiz H.I., Varca G.H.C., Lugao A.B., Bucio E., "Smart Polymers and Coatings Obtained by Ionizing Radiation: Synthesis and Biomedical Applications" Open J Poly Chem, 2015; 5: 17-33.

Paula H.C.B., Gomes F.J.S., Paula R.C.M., "Swelling studies of chitosan/cashew nut gum physical gels" Carbo Poly, 2002; 48: 313-318.

Rai M., Yadav A., Gade A. Silver nanoparticles as a new generation of antimicrobials. Biotechnology Advances, 2009; 27: 76-83.

Seddiki N., Aliouche D., "Synthesis, rheological behavior and swelling properties of copolymer hydrogels based on poly $(\mathrm{N}$ isopropylacrylamide) with hydrophilic monomers", Bull Chem Soc Ethio, 2013; 27: 447-457.

Sekhar E.C., Sudana Rao K. M., Eswaramma S., Krishna Rao K.S.V. , Raju R.R., "Development of Gelatin-Lignosulfonic acid Blend Microspheres for Controlled Release of an Anti-Malarial Drug (Pyronaridine)" Ind J Adv Chem Sci, 2014; 2: 228-237.

Siraj S., Rao K.M., Sudhakar P., "A Green Approach to Synthesize Silver Nanoparticles in Starch-co-Poly(acrylamide) Hydrogels by Tridax procumbens Leaf Extract and Their Antibacterial Activity", Int J Carb Chem, 2013, Article ID 539636, 10 pages, 2013. doi:10.1155/2013/539636.

Sudana Rao K. M., Mallikarjuna B., Krishna Rao K.S.V., Siraj S., Chowdoji Rao K., Subha M.C.S., "Novel thermo/pH sensitive nanogels composed from poly(N-vinylcaprolactam) for controlled release of an anticancer drug" Colloid Surf. B: Biointerf, 2013; 102, 891-897.

Totolin M.I., Cazacu G., "Nanoparticles based on modified lignins with biocide properties" Pim Publishing House, 2010; Iasi, 195.

Tiina E. Nypel., Carlos A., Carrilloa and Orlando J. Rojas. Lignin supracolloids synthesized from (W/O) microemulsions: use in the interfacial stabilization of Pickering systems and organic carriers for silver metal. Soft Matter, 2015; 11: 2046.

Vasireddy R.K., Paul R., Mitra A.K., "Green Synthesis of Silver Nanoparticles and the Study of Optical Properties". Nanomater. nanotechnol., 2012; 2, Art. 8:2012.

Victor A., Oliveira, Tacia C., Veloso, Versiane A., Leao, Claudio G., dos Santos, Vagner R., Botaro, "Hydrogels of cellulose acetate crosslinked with pyromellitic dianhydride: part I: synthesis and swelling kinetics" Quimica Nova, 2013; 36: 102-106.

Vimala K., Mohan Y.M., Varaprasad K., Reddy N.N., Ravindra S., Naidu N.S., Raju K.M., "Fabrication of Curcumin Encapsulated Chitosan-PVA Silver Nanocomposite Films for Improved Antimicrobial Activity”. J Biomat Nanobiot, 2011; 2: 55-64.

Zhang Q., Chuang K.T., "Adsorption of organic pollutants from effluents of a Kraft pulp mill on activated carbon and polymer resin:" Adv Env Res, 2001; 5: 251-258.

\section{How to cite this article:}

Espenti CS, Rao KSVK, Rao KMS. Lignosulfonic Acid Based Hydrogel Nanocomposites for Antimicrobial Application. J App Pharm Sci, 2016; 6 (10): 055-062. 